\title{
IPR Protection on Design Industries in China
}

\author{
Weiwei $\mathrm{Hu}{ }^{*}$ \\ Intellectual Property Research Institute, University of Xiamen, China \\ Helusi420hw@163.com
}

Keywords: CCIs, design industry, IPR protection

Abstract. Culture and creative industries (CCIs) have been increasingly integrated into the policy agenda of both developed and developing countries. Design is the most important creative industry for the Chinese mainland. This paper wants to discuss design industries esp. its intellectual property right (IPR) protection in China, some problems in practice and present some suggestions hoping a healthy development for design industries in the future.

\section{Introduction}

In this era of extraordinary change and globalization, many acknowledge that creativity and innovation are now driving the new economy. Organizations and even economic regions that embrace creativity generate significantly higher revenue and provide greater stability into the future. [1]

Culture and creative industries (CCIs) have been increasingly integrated into the policy agenda of both developed and developing countries. The concept of Creative Industry is newly invented in UK within Creative Industries Mapping Document of 1998, then again in 2001 issued by the UK Department of Culture, Media and Sport (DCMS). The study defines Creative Industries as: those industries which have their origin in individual creativity, skill and talent and which have a potential for wealth and job creation through the generation and exploitation of intellectual property.

The UK's study remains as a pioneering model for many countries to emulate even though the definition is not as same as the UK model. The name and content of cultural and creative industry in different countries and districts are different in some aspects e.g. in the States it is called copyright industries, in Hong Kong it is called creative industry and in Mainland China and Taiwan it is called cultural and creative industry.

Today, competitiveness rests on the ability to create emotional ties with consumers that go beyond the price or the functionality of products. Aesthetic, meaning, social significance are key aspects of the experience economy. Culture, creative industries and intellectual property are key drivers of this intangible economy.[2]

The PRC Labor and Social Security Publishing House (CLSSPH) described "Creative Industries" as: "Creative Industries include performing arts, film-TV, publishing, art and antiques, music, advertising, digital entertainment, software, animation, fashion and product design, craft and so on." China's State Council, the Cabinet, on March14, 2014 further released plans aimed at promoting the integration of the creative and design service industries with the real economy.

Chinese President Xi Jinping even pointed out : "The integration of the creative and design service sectors with other relative traditional trades will serve as an effective method to expand the development of the cultural industry."[3]

Design is the most important creative industry for the Chinese mainland. There is a tangible desire to see a shift from "Made in China" to "Designed in China" — many of China's designers are returnees who have brought home not only valuable skills and experience but considerable ambition. Cities like Beijing and Shanghai have built a number of specialist design institutes within the so called 'knowledge centers' with the aim of differentiating them within China and building economic strength - Shenzhen has for instance become a UNESCO City of Design. [4]Therefore, this paper wants to discuss design industries esp. its intellectual property right (IPR) protection in 
China, some problems in practice and present some suggestions hoping a healthy development for design industries in the future.

\section{IPR protection in China for design industries}

\section{(1)Patent}

In China designs are protected as patents, while in the EU for example they are protected as design rights as such.

\section{A. Legal Definition of Design Patent}

The Patent Law of the People's Republic of China defines design to any new shape, pattern, or their combination, or the combination of color and shape or pattern, of a product, which creates an aesthetic feeling and is fit for industrial application. The exclusivity granted by the law upon the inventor/owner is only related to the outer appearance of the product and does not concern its technical function or which are instead the protected solutions of an invention patent and a utility model.

As to the outer appearance, this means the overall visual effect of the patented product's design compared to the latest common forms of that same design in the specific industrial field.

\section{B. First to File Rule and Preliminary Examination}

According to the Chinese Law, the entity or individual who seeks for the commercial exploitation of its design, and for its protection, has to apply to the Chinese Patent Office. Patents are normally granted within 18 months from the filing date.

Prior use has no legal relevance as to the acquisition of the right of exclusivity over the invention. Only the one who files the related application can than later claim such exclusive patent right. Prior use, save few exceptions, can only cause a loss of novelty of the new design and consequently affect its validity. This is one of the purest examples of the "first-to-file" rule characterizing IPR protection in China. Unlike in Europe and the US, prior use is not legally relevant as to the establishment of ownership.

According to Article 40 of the Patent Law in force, utility models and design patents must be granted immediately upon preliminary examination if no formal errors are found in the application. This article establishes the legal base for the rule of mere formal examination of design patent applications, in contrast with the principle of formal and substantive examination of invention patent applications set forth by the same patent law in Articles 35.

Both rules above have given way to third parties in bad faith to file junk design patents, i.e. patents lacking novelty because already in the state of the art, for either internal, tax purposes (i.e. to show portfolios with the aim of obtaining local government subsidies and tax discounts) or for preventing or disturbing competitors portfolio and support infringing activities.

In sum, it is not infrequent to find that the shape of a certain product has been patented by many other third parties aside from the first inventor filings. In this respect, the Chinese Patent Office has tried to extend the interpretation of "preliminary examination" of Article 40 of the Patent Law to include the possibility for a patent examiner to conduct patent searches as to establish the obvious lack of novelty of a design patent in case of "abnormal applications (...) such as an application obviously plagiarizing prior art or repeated submission of an application with substantially identical content".

\section{Patentability and Grace Period}

A design patent to be valid must be "novel", i.e. it cannot be a design made known to the public inside and outside China at the time of the filing date, and that before the filing date no entity or individual shall have filed an application with the patent administrative department under the State Council, nor recorded any such design on patent-related documents officially published and announced after the filing date (again First to File rule). Furthermore, in order to be valid, a design must be distinctively different from existing designs or a combination of any existing design features for the product in question and must not be in conflict with any rights already obtained lawfully by another party before the filing date (i.e. trademarks and copyrights). 
Novelty in China is lost if the product's shape is disclosed by the right holder before having filed a patent in China. This occurrence is more common than people may believe, especially because of the differences among different national legislations as to the accordance of grace periods to certain types of use of an invention before its date of filing.

It is important again to remark that in light of the mere formal examination of designs, their validity is normally checked out during an invalidation proceeding. This means that even if a design patent is granted, this may not mean that such design is really enforceable.

In sum, when you file design patents in China you must make sure that you have not unduly disclosed it by prior use or publication abroad, unless such disclosure was either done by third parties without the right holder's consent, or was done at specific exhibitions or academic events approved by the Chinese Government.

\section{Enforcement of design Patents (Identity/similarity)}

The Interpretation of the Supreme People's Court of December 28, 2009 on Patent Disputes gives some clarifications as to determination of identity/similarity in case of a judicial dispute over a design patent infringement. First of all, the determination of identity/similarity between designs in an infringement lawsuit or in an invalidation action must be conducted between the patent and the alleged infringing product, while the patented product can be taken as most as a reference.

Also, an infringement can exist only between goods belonging on the identical or similar class of products. The criteria for such determination is based on the identification of the normal use of the relevant products, their functions and sales, in light of the brief explanation of the design made by the patentee and the International Classification for Industrial Designs.

But how the court has to judge whether the designs are identical or similar? Mostly it can refer to a level of knowledge and a cognitive ability of a normal consumer of the product whose design is the object of litigation/invalidation. In particular, the court has to comprehensively judge whether the designs are identical or similar in the light of the overall visual effect given to the designs by their aesthetical features. Conversely, the court must not consider the design features mainly defined by the technical function, the product material and internal structures which do not influence the overall visual effect.

In general, the overall visual effect of the design will be notably influenced in the following circumstances:

a. The portions which can be observed easily and directly when the product is normally used, compared with other portions of the product;

b. The features of the patented design which are different from the existing design, compared with other features of the patented design.

Where there is no difference between the accused design and the patented design in the overall visual effect, the court will determine the two designs as to be identical; where there is no-substantive difference in the overall visual effect, the court will judge the two designs to be similar. Mere decorative patterns cannot take away the feeling of similar visual effect.

Generally, an experienced Chinese IP court such as Beijing or Shanghai, will have a much consolidated jurisprudence and there should be but little surprises as to the identity/similarity determination process.

\section{(2) Unfair Competition}

Article 5 of Chinese Unfair Competition Law provides that business operators shall not use without authorization, the names, packaging or decoration peculiar to well-known goods or using names, packaging or decoration similar to those of well-known goods so that their goods are confused with the well-known goods of others, causing buyers to mistake them for the well-known goods of others. This norm may be indeed a possible alternative as long as the design in question concerns the "trade dress" of a product. Most notable example of such case was the recognition of protection under this article to the world famous box of Ferrero Roche chocolates.[5]

In a more recent decision, the Supreme People's Court has extended the definition of "decoration" of a product to the shape of a product's outer design. According to the court, the shape of a product's design can in certain cases have a decorative function, and therefore can be protected 
under article 5 paragraph 2 of the Unfair Competition Law, as the so-called "trade-dress". The relevant design features of a product with a pure aesthetical value which are not necessitated by any technical effect or function can be protected under article 5 as long as they can be intended and used as a decorative element of the product itself and as long as such shape has become known to the relevant Chinese markets.

According to the court, limiting the function of decoration to the words, patterns or colours attached to a product, would in fact exclude the shape of the product when it has mere or predominant decorative value, thus improperly restricting the purpose of its commercial and identification functions. The court goes on arguing that, if the product has a creative feature (i.e., its shape) which gives to it a certain aesthetic value, makes it artistically unique and creates an unmistakable relation between the shape and the brand core values; this feature becomes a statement to the quality and creativity of the brand itself. An outer design can possess therefore an identification value, not just a mere aesthetical one, if it has a certain uniqueness in its market segment, and become itself an element of distinction of its own origin, a brand statement.

\section{(3) Copyright}

The major challenge of using copyright instead of design is given by the fact that copyright does not cover by definition industrial products. That is why we have a differentiation between designs (aesthetic value of vile products) and copyright (high intellectual achievement in a unique work). Granting copyright in the overall shape of a shoe or a bag or a coffee machine will conflict with the commercial and economic sense behind IP rights. In sum, it would create an unjust monopoly over a rather common intellectual achievement, whereby copyright should be granted only to more complex intellectual works. This alone seems in principle to exclude the possibility of copyright protection to the outer shape of industrial products.

On the other hand, there has been a massive vilification of copyright, by including into it many kinds of not so high intellectual works. We can think for example, about the copyright protection now extended to pictures and layouts of commercial catalogues or web-pages!

In order to build up a copyright case, the design owner must prove that he has a copyright on his product's design, providing evidence of the creative efforts made for coming up with such a design, as well as its differentiation from other products. He shall prove also that the product can be object of a copyright, as it is a graphical or stereoscopic work of fine art expressed by lines, colour or other measures such as drawings, calligraphy or sculpture. Furthermore, if a company has registered a copyright be depositing pictures or drawings, such copyright extends also to their three dimensional reproduction.

Afterwards he plaintiff will have to prove not only that he owns such copyright, but that he has enjoyed the right prior to the alleged infringement, i.e. launching, promoting and selling the product in China at the earliest date. Also, the right holder shall prove that the infringer knew or should have known his copyright. Such evidence can often be of an indirect nature only, i.e. by showing to the court how difficult it was for the defendant not to know or have known about that product in light of the promotional activities, advertising campaigns or any other attempt by the Plaintiff to make the product public in China. Then, finally, the copyright holder needs to prove the substantial similarity between the original and the fake product, being for this purpose not necessary their identity: the differences do not have to be sufficient to eliminate visual similarity, and to affect the overall feeling of analogy from the perspective of a lay person.

In practice, when a right holder finds itself with no other means of protecting its design in China, he may indeed try to use copyright as an alternative. Even if a success is on the balance, or mostly unlikely, the lawsuit may still serve some tactical purposes, such as winning time to change the design and apply for a new patent, or to put the infringer under pressure and try to negotiate a back license or a transfer of the design rights.

\section{(4) Trademark}

A design could be also protected as a three dimensional trademark. However, the major obstacle to such possibility is the fact that designs refer exactly to the definition of the aesthetic characteristics of the product itself, which make them thus not suitable for trademark protection. A 
protection possibility exists as long as a certain design acquires such a high distinctive character of a degree so high as to abstract itself from the product.

Even if this were the case, the right holder should also prove that the shape is well known and therefore can be protected as a well-known unregistered trademark. In fact, as for designs, only registered trademarks are protected in China, with the sole exception of well-known unregistered trademarks. Such remedy is therefore not viable. [6]

\section{Enforcement Problems of Design Patent in Practice}

While China's Patent Laws today are world-class, the challenges involved in enforcement remain considerable. This fact, coupled with rampant infringement, forces many prospective foreign design patent applicants to re-consider and frequently abandon plans to file many (or any) design patent applications in China.

\section{(1)Patent coverage must be expanded}

In China, design protection is directed to physical objects and excludes products with graphical user interface (GUI) from design patent protection. The GUIs, such as icons, menus, and pointing devices, allow humans to interact with their computers and cell phones. The protection of GUIs in the United States is mainly conducted through the patent law. Different from China, the United States requires substantive examinations in design patents. It also allows the same subject matter to be eligible under various possible overlapping IP protections. Protection of design patents is provided in Articles 171, 172 and 173 under Chapter 16 of the current U.S. patent laws.

In 2001, EU issued the "Council Regulation (EC) No. 6/2002 of 12th December 2001 on Community designs" (Council Regulation (EC) No. 6/2002). The latter create the "Community design right," and incorporated the concepts of "Unregistered Community Design" (UCD) and "Registered Community Design" (RCD). According to it, a single application for Community design enables the subject matter to be protected and enjoy the same rights in all EU member countries. In Japan, the protection for GUI completely results from country protection to the electronic industry. [7]

However, China now has the opportunity to join the majority of countries that grant design patent protection for GUIs. David Kappos, undersecretary of Commerce for Intellectual Property and director of the USPTO, stated that "design protection of GUIs is important in addressing the increasing phenomenon of migration of real objects to virtual objects, such as cell phones or laptops, or the GUI of a refrigerator to enable its remote control. There is also a need to provide more robust protection for designs in the borderless computing "cloud."'

\section{(2) “Junk" patents filings must be policed}

Because the system of granting design patents does not require SIPO to undertake a substantive examination, the filing of frivolous design patent applications is common. The resulting "junk" patents are either based on previously known designs or issued design patents with or without minor modifications. For example, a licensee of a design patent re-submitted the same design in his own design patent to "double" and thereby "improve" the rights of the legitimate design patent holder-all without the authorization of the licensor. To reduce the number of junk patents, China could adopt a system of substantive examination. This step would be consistent with China's push for increased domestic innovation. Other possible modifications include the requirement that an oath or declaration attesting to originality of the design be submitted with the application (currently not required) or the requirement of a SIPO-issued evaluation report prior to the filing of an infringement action. Along these lines, penalties for knowingly asserting an invalid design patent should be levied. A separate opposition proceeding should also be established for design patents. [8]

\section{Conclusion}

It should be noticed that regarding the first problem, the SIPO published Draft of the Fourth Amendments to the Chinese Patent Law (for public comments) on April 1, 2015, the Draft proposes 
to properly expand patentable subjects and prolong patent term of designs[9], if this proposal will be endorsed, it can to breathe life into the protection of design industries.

Besides, according to the Annual Work Report of the Supreme People's Court on Intellectual Property Rights Cases (2013), one of the basic rules and characteristics of hearing IPR and competition cases is cases involved software, anime and applied arts etc. regarding CCIs continuously increase. As to design industries, in accordance with the captioned discussion, it is most important to protect their product designs by filing them in China as a design patent. Failure to do so will have no effective remedies but mere palliatives of tactical nature such as filing copyright infringement actions for negotiating some settlement with the counterfeiters.

Also, having trademarks to protect a product is not enough. If the shape of the product becomes more famous than the brand, the risk is that after a few successful trademark enforcements, the counterfeiters will just remove the trademark and continue to infringe the product design. In sum, even if a company may have (and most times, they do have) other IP rights regularly filed in China such as trademark and copyrights, this does not protect them if the infringer targets only the design of the product. [10]

\section{References}

[1] Hendrik van der Pol, Key role of cultural and creative industries in the economy, http://www.oecd.org/site/worldforum06/38703999.pdf.

[2],[4]Mapping the Cultural and Creative Sectors in the EU and China: A Working Paper in support to the development of an EU-China Cultural and Creative Industries' (CCIs) platform(2011) p.4 \& p.15. Also available at http://www.ipr2.org/index.php?option=com_content\&view $=$ article\&catid=109:support-for-right-holders\&id=1344:mapping-the-cultural-and-creative-sectors-in -the-eu-and-china-a-working-paper-in-support-to-the-development-of-an-eu-china-cultural-and-crea tive-industries-ccis-platform $\&$ Itemid $=85$

[3] China unveils policy to boost creative industry, http://news.xinhuanet.com/english/china/2014-03/14/c_133186858.htm,2014-03-14.

[5] Italian Ferrero Co., Ltd. (Ferrero) v. Mengtesha Food Co., Ltd. and Tianjin Economic and Technology Developing Zone Zhengyuan Distributing Co., Ltd.,MinsantiziNo.3 civil judgment by Supreme People's Court,March 24, 2008.

[6], [10] Paolo Beconcini, Vittorio Franzese, Industrial Design Protection in China

https://www.linkedin.com/pulse/industrial-design-protection-china-vittorio-franzese,2015-2-17.

[7] Li Xiaowu ,Status of GUI protection in different countries, Chinaipmagazine,Issue 51,Oct. 2012. Also available at http://www.chinaipmagazine.com/en/journal-show.asp?id=884.

[8] Thomas T. Moga, Obtaining and Enforcing Design Patents in China http://www.chinabusinessreview.com/obtaining-and-enforcing-design-patents-in-china/

[9] Main amendments in draft of fourth amendments to the Chinese Patent Lawhttp:/www.chinalawinsight.com/2015/05/articles/intellectual-property/main-amendments-in-dr aft-of-fourth-amendments-to-the-chinese-patent-law/,2015-5-15. 